\title{
Effect of using different U/S probe Standoff materials in image geometry for interventional procedures: the example of prostate
}

\author{
Stefanos Diamantopoulos, BS', Natasa Milickovic, PhD', Saeed Butt, BS', Zaira Katsilieri, MSc', Vasiliki Kefala, MSc', \\ Pawel Zogal, MSc', George Sakas, PhD³, Dimos Baltas, PhD' \\ IDepartment of Medical Physics \& Engineering, Klinikum Offenbach GmbH, Offenbach am Main, Germany, 2Medcom GmbH, Darmstadt, \\ Germany, ${ }^{3}$ Fraunhofer IGD (Cognitive computing and medical imaging), Darmstadt, Germany
}

\begin{abstract}
Purpose: This study investigates the distortion of geometry of catheters and anatomy in acquired U/S images, caused by utilizing various stand-off materials for covering a transrectal bi-planar ultrasound probe in HDR and LDR prostate brachytherapy, biopsy and other interventional procedures. Furthermore, an evaluation of currently established waterbath based quality assurance (QA) procedures is presented.

Material and methods: Image acquisitions of an ultrasound QA setup were carried out at $5 \mathrm{MHz}$ and $7 \mathrm{MHz}$. The U/S probe was covered by EA 4015 Silicone Standoff kit, or UA0059 Endocavity balloon filled either with water or one of the following: $40 \mathrm{ml}$ of Endosge ${ }^{\circledR}$, Instillagel ${ }^{\circledR}$, Ultraschall gel or Space OAR ${ }^{\mathrm{TM}}$ gel. The differences between images were recorded. Consequently, the dosimetric impact of the observed image distortion was investigated, using a tissue equivalent ultrasound prostate phantom - Model number 053 (CIRS Inc., Norfolk, VA, USA).

Results: By using the EA 4015 Silicone Standoff kit in normal water with sound speed of $1525 \mathrm{~m} / \mathrm{s}$, a 3 mm needle shift was observed. The expansion of objects appeared in radial direction. The shift deforms also the PTV (prostate in our case) and other organs at risk (OARs) in the same way leading to overestimation of volume and underestimation of the dose. On the other hand, Instillage ${ }^{\circledR}$ and Space OAR ${ }^{\mathrm{TM}}$ "shrinks" objects in an ultrasound image for $0.65 \mathrm{~mm}$ and $0.40 \mathrm{~mm}$, respectively.

Conclusions: The use of EA 4015 Silicone Standoff kit for image acquisition, leads to erroneous contouring of PTV and OARs and reconstruction and placement of catheters, which results to incorrect dose calculation during prostate brachytherapy. Moreover, the reliability of QA procedures lies mostly in the right temperature of the water used for accurate simulation of real conditions of transrectal ultrasound imaging.
\end{abstract}

Key words: ultrasound, needle displacement, image distortion, prostate brachytherapy.

\section{Purpose}

In HDR and LDR prostate brachytherapy, needle implantation is guided by real-time ultrasound (U/S) images acquired by using a transrectal bi-planar probe. This probe is covered by a UA0059 Endocavity balloon (CIVCO, Kalona, Iowa, USA: see Fig. 1A) filled with water. The purpose of this balloon is double. Firstly, to provide smoother transmission (coupling) of ultrasound signals between ultrasound probe and human tissue and thus to improve image quality. Secondly, to move the prostate gland according to template coordinates, by adding or removing the proper amount of water in it. Although being successfully used in clinical routine, this equipment is consumable, and after one use it has to be replaced, increasing the cost of every treatment session. On the other hand, EA 4015
Silicone Standoff kit (CIVCO, Kalona, Iowa, USA: Fig. 1B) seems to be a potential solution to the above mentioned disadvantage, as it can be sterilized or used with condoms and reused. The question arise if EA 4015 Silicone Standoff kit can be utilized instead of UA0059 Endocavity Balloon, without distorting imaging of patient's anatomy and needle positioning. This appears as silicone rubber has different acoustic properties than those of water. Any kind of geometry transformation during image acquisition could possibly lead to wrong contouring, reconstruction and placement of needles, and further, to incorrect dose calculation [1-10].

The second part of this study investigates the impact of other hydro-gel type materials on quality of ultrasound imaging. U/S-imaging algorithms are based on the speed of sound in soft tissue $[11,12]$. However, established quality

\footnotetext{
Address for correspondence: Natasa Milickovic, PhD, Offenbach Clinic, Department of Medical Physics \& Received: 18.08 .11 Engineering, Offenbach am Main, Germany, Starkenburgring 66, Offenbach am Main, Germany, 

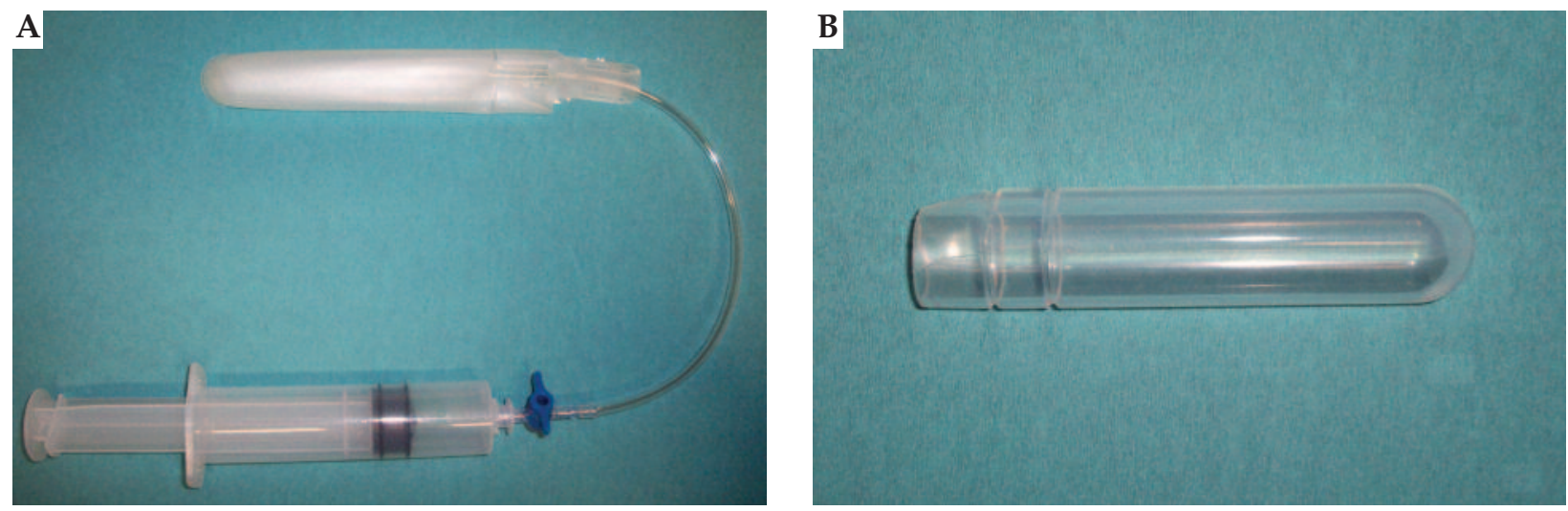

Fig. 1. Two different ways of covering the U/S probe during the image acquisition: (A) UA0059 Endocavity balloon and (B) EA 4015 Silicone Standoff kit (both by CIVCO, Kalona, Iowa, USA)

assurance procedures for adjustment of U/S-image geometry and template position are based on a water-bath experimental setup. Therefore, in addition, the purpose of this research is to evaluate the accuracy of water-bath based quality assurance procedures.

\section{Material and methods}

\section{Theoretical calculations}

\section{Speed of sound in normal water}

In this experiment, normal or tap water (not distilled) was used, which contained some impurities (ion concentration). In contrast to pure water, in which sound velocity can be defined only as a function of temperature, the speed of sound in normal water depends on temperature, salinity, and pressure [13-24]. For the theoretical calculations and the experimental procedure a fixed temperature of $37.7^{\circ} \mathrm{C}$ was selected, thus simulating rectum conditions. For the calculation of water salinity (concentration of mineral salts dissolved in the water or total dissolved salts: TDS), three measurements of electrical conductivity (EC) were performed. They were made by a GMH 3410 operating manual conductivity measuring instrument (Greisinger electronic $\mathrm{GmbH}$, Regenstauf, Germany ${ }^{\circledR}$ ) in a sample of the utilized water, at $25^{\circ} \mathrm{C}$ (reference temperature). The mean value was used to calculate TDS from equation 1 (see Table 1):

$$
\operatorname{TDS}(\%)=0.00064 \times \mathrm{EC}(\mu \mathrm{Sm} / \mathrm{cm})
$$

Hydrostatic pressure was calculated using the Equation 2:

$$
\mathrm{P}_{\text {tot }}=\mathrm{P}_{\mathrm{atm}}+\mathrm{r} \times \mathrm{g} \times \mathrm{h}
$$

where $P_{a t m}$ is the atmospheric pressure, $r$ is the density of the water, $g$ is the acceleration of gravity and $h$ is the depth in water where the sound velocity needs to be calculated. Density of the water $r$ was calculated using the McCutcheon-Martin equation [13], see Table 1. The speed of sound in water as a function of temperature, pressure and salinity was derived from Chen-Millero equation [14], see Table 1. It is valid in a range that meets our requirements: temperature 0 to $40^{\circ} \mathrm{C}$, salinity 0 to 40 parts per thousand, pressure 0 to 1000 bar.

\section{Speed of sound in distilled water}

Speed of sound in distilled water at $37.7^{\circ} \mathrm{C}$ was calculated by the experimental equations found in bibliography [13-24].

\section{Expected image distortion with the use of EA 4015 Silicone Standoff kit}

To predict the image distortion, we need additionally the speed of sound in silicone rubber. For the determination of this speed, the results from Hachiya et al. [15] were employed. According to their experimental curve, speed of sound in silicone rubber at $37.7^{\circ} \mathrm{C}$ corresponds to $981.2 \mathrm{~m} / \mathrm{s}$.

\section{Potential calibration errors}

Any deviation of speed of sound in water in test tank from the U/S calibration speed of $1540 \mathrm{~m} / \mathrm{s}$ would lead to inaccurate quality assurance tests. Therefore, an estimation of potential calibration errors was done, assuming that percentage acoustic velocity deviation of each water quality from $1540 \mathrm{~m} / \mathrm{s}$ have the same percentage radial effect in pulse-echo distance. Extended calculations of theoretical needle displacement are presented in the appendix.

Table 1. Physical properties of the utilized tap water: temperature $T$, electrical conductivity $(E C)$, total dissolved salts (salinity: TDS), water density $r$ and pressure $P$. Speed of sound in water as a function of temperature, pressure and salinity was derived from Chen-Millero equation [14] which is valid in a range of temperature between 0 to $40^{\circ} \mathrm{C}$, salinity of 0 to 40 parts per thousand and pressure of 0 to 1000 bar

\begin{tabular}{lccccc}
$\begin{array}{l}\mathrm{T} \\
\left({ }^{\circ} \mathrm{C}\right)\end{array}$ & $\begin{array}{c}\mathrm{EC} \\
(\mu \mathrm{Sm} / \mathrm{cm})\end{array}$ & $\begin{array}{c}\mathrm{S} \\
(\%)\end{array}$ & $\begin{array}{c}\text { Density } \\
(\mathrm{g} / \mathrm{l})\end{array}$ & $\begin{array}{c}\text { Pressure } \\
(\mathrm{bar})\end{array}$ & $\begin{array}{c}\text { Sound speed } \\
(\mathrm{m} / \mathrm{s})\end{array}$ \\
\hline 37.7 & 502 & 0.321 & 0.993 & 0.101 & 1525.421
\end{tabular}




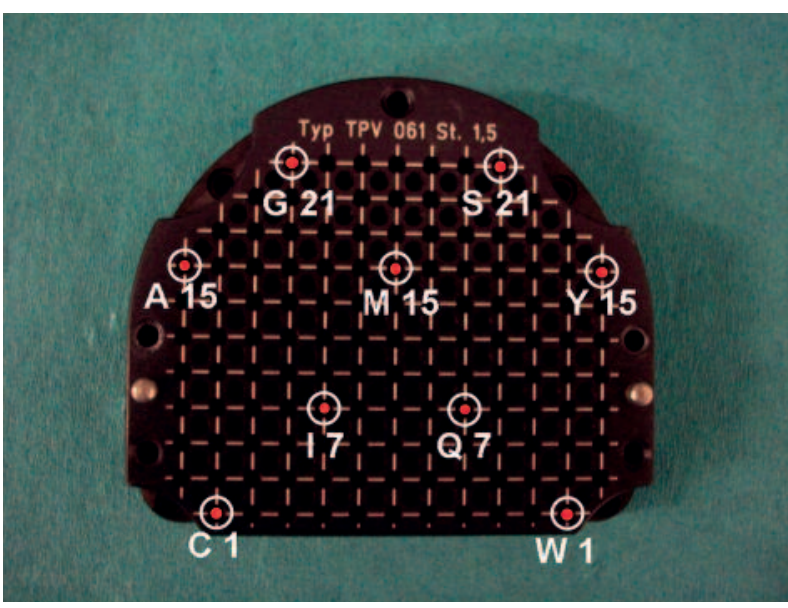

Fig. 2. Needle positions (shown with a red circles) on a High Resolution TPV 061 template (GfM-Medizintechnik $\mathrm{mbH}$, Darmstadt, Germany). This setup with 9 stainless steel trocar needles of $1.5 \mathrm{~mm} \times 200 \mathrm{~mm}$ (Nucletron B.V., Veenendaal, Netherlands) was used to investigate the "shift effect"

\section{Experimental procedure}

\section{Setup}

On a High Resolution TPV 061 template (GfM-Medizintechnik mbH, Darmstadt, Germany $\left.{ }^{\circledR}\right)$, 9 stainless steel trocar needles of $1.5 \mathrm{~mm}$ x $200 \mathrm{~mm}$ (Nucletron B.V., Veenendaal, Netherlands) were placed at the positions that are shown in Fig. 2. The choice of the holes was made in such a way to investigate the "shift effect" in ultrasound image, caused by the materials under test, at the central area and edge positions of the template symmetrically. The distances between the holes were large enough, ensuring no overlapping of the needles caused by shadowing artefacts at the acquired ultrasound images.

The TPV 061 template was connected to a GfM mechanical stepper (GfM-Medizintechnik mbH, Darmstadt, Germany ${ }^{\circledR}$ ) and a CLA 6.5/R10/2x128/BIP-1224 ultrasound probe (Vermon SA, Tours, France ${ }^{\circledR}$ ). It was placed vertically in a tank filled with normal water with a temperature of $37.7^{\circ} \mathrm{C}$. The temperature was measured by a TFX 422 precision thermometer (ebro Electronic $\mathrm{GmbH} \& \mathrm{Co}$. KG, Ingolstadt, Germany ${ }^{\circledR}$ ) and maintained stable during image acquisitions. This was done in order to simulate human rectum environment, see Fig. 3. Subsequently, the probe and the stepper were connected to LogicScan 128 INT-2Z beamformer (Telemed UAB, Vilnius, Lithuania ${ }^{\circledR}$ ) and to BiopSee ${ }^{\circledR}$ 0.9.14 software (MedCom GmbH, Darmstadt, Germany and Pi Medical Ltd. Athens, Greece $\left.{ }^{\circledR}\right)$.

\section{Acquisitions}

The tested materials that covered the U/S probe were: 1) EA 4015 Silicone Standoff kit or 2) UA0059 Endocavity balloon filled with one of the following each time: a) water, $40 \mathrm{ml}$ of Endosge ${ }^{\circledR}$ (Farco-Farma GmbH, Germany ${ }^{\circledR}$ ), b) $40 \mathrm{ml}$ of Instillagel ${ }^{\circledR}$ (Farco-Farma GmbH, Germany ${ }^{\circledR}$ ), c) $40 \mathrm{ml}$ of Ultraschall gel (Dahlhausen \& Co. GmbH, Germany ${ }^{\circledR}$ ). Finally, d) Space OAR ${ }^{\mathrm{TM}} \mathrm{Gel}$ (Augmenix, Waltham,

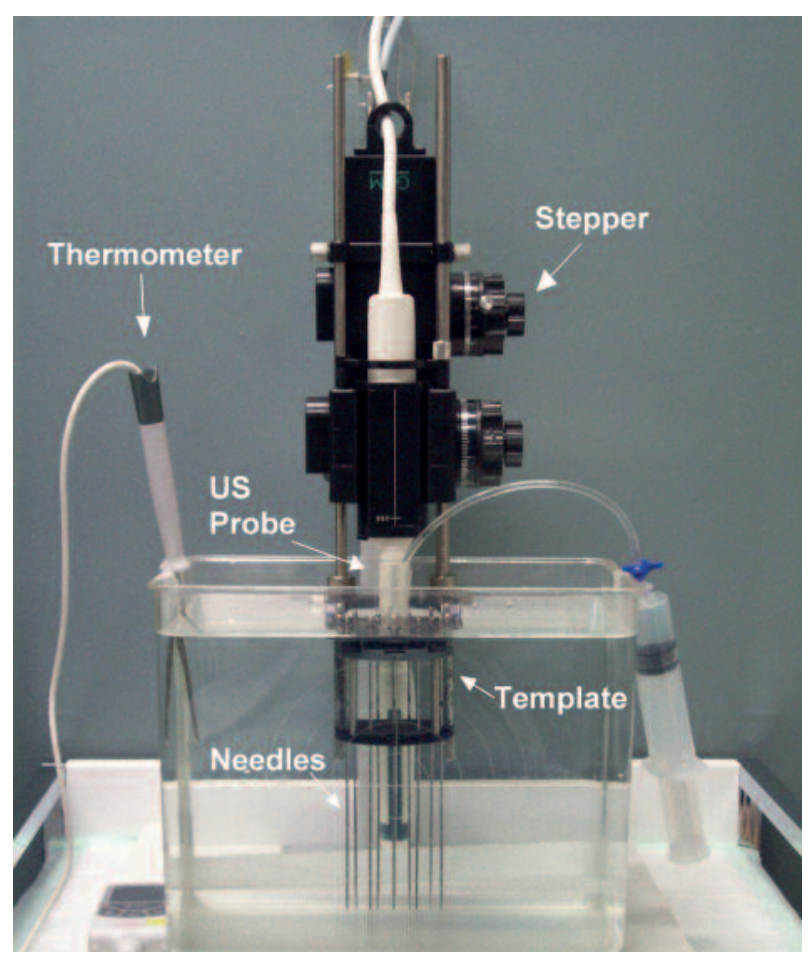

Fig. 3. Experimental setup (front view): The TPV 061 template was connected to a GfM mechanical stepper and a CLA 6.5/R10/2x128/BIP-1224 ultrasound probe. It was placed vertically in a tank filled with normal water with a temperature of $37.7^{\circ} \mathrm{C}$ which was continuously observed by a TFX 422 precision thermometer

MA, USA ${ }^{\circledR}$ ) was injected into a Endocavity balloon and was arranged properly to form a $5.0 \mathrm{~mm}$ layer in front of U/S probe curved array (same thickness as Silicone Standoff kit).

For each available material, acquisitions were carried out at two frequencies: $5 \mathrm{MHz}$ and $7 \mathrm{MHz}$. This was done to make sure if the needle displacement is frequency-dependent. Prior to that, a pair of reference acquisitions at both frequencies was retrieved, with the ultrasound probe being "uncovered" in the water. After completing all acquisition cycles, the coordinates of the centre of each needle in the acquired image sets (centre of the needle fingerprint on U/S images) were reconstructed at the base, reference and apex plane. The position of the reconstructed needles from these image sets was compared with the position of reconstructed needles from the reference image set acquired with uncovered U/S probe in water for both frequencies.

\section{Prostate volumetric analysis}

\section{Theoretical approach}

Based on theoretical calculations of the sound speed in the different materials, it is expected that the use of the Silicone Standoff kit for coverage of the U/S probe during the image set acquisition will lead to volume and anatomical structure deformation and needle displacement. For that reason, the theoretically calculated shift was applied to cylindrical prostate models with various radii and distances from the probe surface. For each prostate model the percentage 


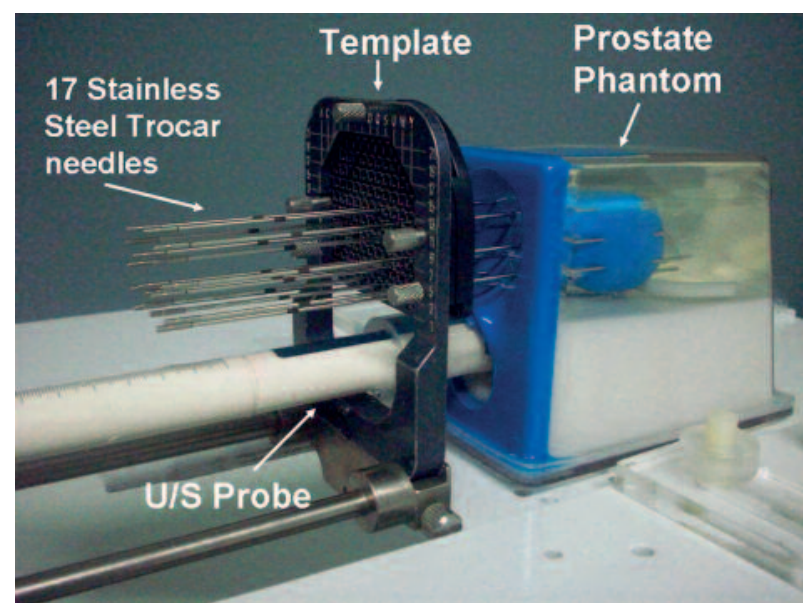

Fig. 4. Tissue equivalent ultrasound prostate phantom Model number 053 (CIRS Inc., Norfolk, VA, USA) arrangement: The TPV 061 template was connected to a GfM mechanical stepper and a ultrasound probe. 17 stainless steel trocar needles were implanted in the prostate phantom

deviation of the distorted volume from the initial one was plotted in dependence on the distance from probe surface.

\section{Experimental prostate volumetric calculations}

In order to verify our theoretical volumetric calculations, the following experiment was designed. Using a tissue equivalent ultrasound prostate phantom - Model number 053 (CIRS Inc., Norfolk, VA, USA ${ }^{\circledR}$ ) and previously mentioned equipment, two image acquisitions were performed (see Fig. 4). During the first acquisition, the ultrasound probe was covered by Silicone Standoff kit, and in the second one the Endocavity balloon was used. The amount of water inserted in the balloon was adjusted to form a layer above probe surface equal to the Silicone Standoff physical thickness of $5 \mathrm{~mm}$, hence to include the same geometry. Afterwards, the prostate volume was contoured for each image set. The two PTV volumes were compared. The results acquired from the theoretical prediction were additionally evaluated.

\section{Dosimetric study}

Using the setup described above, 17 stainless steel trocar needles were implanted in the prostate phantom, using the Endocavity balloon live images (Fig. 4). Afterwards, two image acquisitions were carried out in the previously described way: one was made with Silicone Standoff kit and the second with the use of the U/S probe covered by Endocavity balloon filled with water. The position of needles has remained unchanged all the time. The acquired datasets were transferred to Oncentra ${ }^{\mathrm{TM}}$ Prostate treatment planning system (Nucletron B.V., Veenendaal, Netherlands ${ }^{\circledR}$ ).

Next, the treatment plan $\left(\mathrm{P}_{1}\right)$ was prepared based on the first image set acquired with the U/S probe covered by Silicone Standoff kit. The thickness of the used Silicone Standoff kit was $5 \mathrm{~mm}$. The PTV and OARs were contoured and needles were reconstructed. The plan was calculated utilizing the inverse planning and optimization tool HIPO [25] avail-
Table 2. Clinical protocol (constraints) for HDR brachytherapy of prostate used at our clinic

\begin{tabular}{|c|c|}
\hline Dose-Volume parameter & Value \\
\hline$\overline{D_{90}-\text { Prostate }}$ & $\begin{array}{l}\geq 100 \% \text { of prescription dose: } \\
11.5 \text { Gy }\end{array}$ \\
\hline$V_{100}$ - Prostate & $\geq 90 \%$ \\
\hline $\mathrm{V}_{150}$ - Prostate & $\leq 35 \%$ \\
\hline $\mathrm{D}_{10}$ - Urethra & $\leq 115 \%: 13.2 \mathrm{~Gy}$ \\
\hline $\mathrm{D}_{0.1 \mathrm{~cm}^{3}}$ - Urethra & s120\%: 13.8 Gy \\
\hline $\mathrm{D}_{10}-$ Bladder and $\mathrm{D}_{10}-$ Rectum & $\leq 75 \%: \quad 8.6$ Gy \\
\hline $\mathrm{D}_{0.1 \mathrm{~cm}^{3}}-$ Bladder and $\mathrm{D}_{0.1 \mathrm{~cm}^{3}}-$ Rectum & $\leq 80 \%: \quad 9.2 \mathrm{~Gy}$ \\
\hline \multicolumn{2}{|c|}{$\begin{array}{l}D_{90}: \text { The dose that covers } 90 \% \text { of the PTV volume } \\
V_{100}: \text { The percentage of prostate volume (PTV) that has received at least the } \\
\text { prescription dose }(P D) \\
V_{150} \text { : The percentage of prostate volume (PTV) that has received more than } \\
150 \% \text { of the PD } \\
D_{10}: \text { the highest dose covering } 10 \% \text { of the urethra/rectum/bladder volume } \\
D_{0.1} \mathrm{~cm}^{3}: \text { the dose for the most exposed } 0.1 \mathrm{~cm}^{3} \text { of the urethra/ bladder/rectum }\end{array}$} \\
\hline
\end{tabular}

able in Oncentra Prostate. All dosimetric indices and parameters of the plan satisfied our clinical protocol presented in Table 2. Afterwards, the second image set acquired using the U/S probe covered by Endocavity balloon filled with water was used. The amount of water inserted in the balloon was adjusted to form a layer above probe surface equal to the Silicone Standoff physical thickness of $5 \mathrm{~mm}$. The PTV and OARs were contoured and the needles were reconstructed. The active dwell positions and dwell times calculated in the previously prepared plan $\left(\mathrm{P}_{1}\right)$ were imported into the reconstructed catheters of present image set (Advance Plan Loading procedure in Oncentra Prostate ${ }^{\circledR}$. Without any modification of the imported source dwell positions and times, the plan was created and the 3D dose distribution and the DVHs were calculated. This was considered to be a plan $\left(\mathrm{P}_{2}\right)$ which corresponds to the factual situation. Finally, all dosimetric indices defined in our clinical protocol for both plans $\mathrm{P}_{1}$ and $\mathrm{P}_{2}$ were compared (see Table 2). In addition the Conformal Index [26] (COIN) and the External Index [27] (EI), for both plans were calculated and analysed.

We have compared COIN values including OARs, for the reference/ prescribed dose to PTV. It considers also the conformity of the 3D dose distribution regarding the OARs [26, 28, 29]:

$$
\operatorname{COIN}=c_{1} \times c_{2} \times c_{3}
$$

The coefficient $c_{1}$ is the fraction of the PTV that is enclosed by the prescription dose. The coefficient $c_{2}$ is the fraction of the volume encompassed by the prescription dose that is covered by PTV. It is a measure of how much tissue outside the PTV is covered by the prescription dose. The $c_{3}$ is given as:

$$
c_{3} \stackrel{N_{\mathrm{OAR}}}{=} \prod_{\mathrm{i}=1}^{N_{1}}\left[1-\frac{V_{\text {OAR }}^{i}\left(D>D_{\text {limit }}^{i}\right)}{V_{\text {OAR }}^{i}}\right]
$$

where $N_{O A R}$ is the total number of OARs, $V_{O A R}^{i}$ is the volume of the i-th OAR, $D_{\text {limit }}^{i}$ is the dose limit defined for the 
Table 3. Comparison of theoretical calculations to experimental needle displacement for EA 4015 Silicone Standoff kit

\begin{tabular}{|c|c|c|c|c|c|}
\hline \multicolumn{6}{|c|}{ Shift (mm) } \\
\hline $\begin{array}{l}\text { Freq. } \\
(\mathrm{MHz})\end{array}$ & Experimental & $\begin{array}{l}\text { Theoreticala } \\
\text { in } v_{\text {normal water }}\end{array}$ & $\begin{array}{l}\text { Difference } \\
(\%)^{\mathrm{a}}\end{array}$ & $\begin{array}{l}\text { Theoreticalb } \\
\text { in } v_{\text {soft tissue }}\end{array}$ & $\begin{array}{c}\text { Difference } \\
(\%)^{b}\end{array}$ \\
\hline 5 & $3.03 \pm 0.13$ & 2.77 & -8.6 & 2.80 & -7.6 \\
\hline 7 & $3.04 \pm 0.14$ & 2.77 & -8.9 & 2.80 & -7.9 \\
\hline
\end{tabular}

aTheoretical needle shift, in case of utilizing the real speed of sound in normal water in U/S software (Appendix)

bTheoretical needle shift with actual software (Appendix)

Table 4. Absolute values of the average measured needle shift per standoff material used

\begin{tabular}{lll}
\multirow{2}{*}{ Material } & \multicolumn{1}{c}{$5 \mathrm{MHz}$} & $7 \mathrm{MHz}$ \\
\cline { 2 - 3 } & Shift $(\mathrm{mm})$ & Shift $(\mathrm{mm})$ \\
\hline Silicone Standoff kit & $3.03 \pm 0.11$ & $3.05 \pm 0.13$ \\
\hline Endocavity balloon filled with: & & \\
\hline water & $0.26 \pm 0.14$ & $0.28 \pm 0.21$ \\
\hline Endosgel ${ }^{\circledR}$ & $0.29 \pm 0.16$ & $0.20 \pm 0.12$ \\
\hline Instillage| ${ }^{\circledR}$ & $0.72 \pm 0.20$ & $0.62 \pm 0.10$ \\
\hline Ultrashall gel & $0.32 \pm 0.25$ & $0.29 \pm 0.17$ \\
\hline Space OAR & & \\
\hline
\end{tabular}

i-th OAR and $V_{O A R}^{i}\left(D>D_{\text {limit }}^{i}\right)$ is the volume of the $\mathrm{i}$-th OAR that receives a dose that exceeds the dose limit $D_{\text {limit }}^{i}$.

It is important to mention that while the coefficients $c_{1}$ and $c_{2}$ depend on the dose value under consideration, the coefficient $c_{3}$ depends only on the dose limits defined for each of OARs. The EI [27] is the ratio of the normal tissue volume outside of the PTV that receives a dose equal to or greater than the reference dose to the volume of the PTV. In this way the influence of using the Silicone Standoff kit on the 3D-dosimetry can be investigated.

\section{Results}

\section{Theoretical calculations of the speed of sound}

The speed of sound at $37.7^{\circ}$ for the materials we used in our analyses were as follows: for distilled water $1524.9 \mathrm{~m} / \mathrm{s}$, normal water $1525.4 \mathrm{~m} / \mathrm{s}$, soft tissue $1540.0 \mathrm{~m} / \mathrm{s}$, and silicone rubber $981.0 \mathrm{~m} / \mathrm{s}$. The speed of sound in soft tissue was considered to be $1540 \mathrm{~m} / \mathrm{s}$, as referred in bibliography [11, 12].

\section{Experimental evaluation of effect of materials on $U / S$ image geometry}

\section{EA 4015 Silicone Standoff kit}

Using a Silicone Standoff kit, we observed a radial needle shift of about $3 \mathrm{~mm}$ (Tables 3 and 4) at both frequencies (Figs. 5 and 6). Experimentally evaluated shift was in a good agreement with theoretical estimation, as displayed in Table 3. In addition, we found out that the needle displacement was independent from its distance from

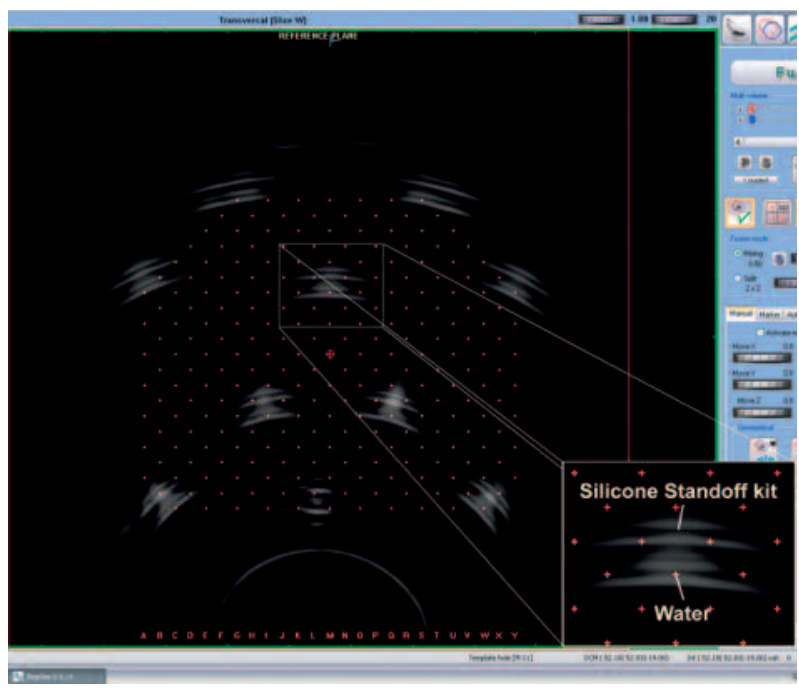

Fig. 5. Fused images (BiopSee ${ }^{\circledR} 0.9 .14$ software): reference image (acquisition made using an Endocavity balloon filled with water) and image from acquisition made utilizing a Silicone Standoff kit at reference plane at $5 \mathrm{MHz}$

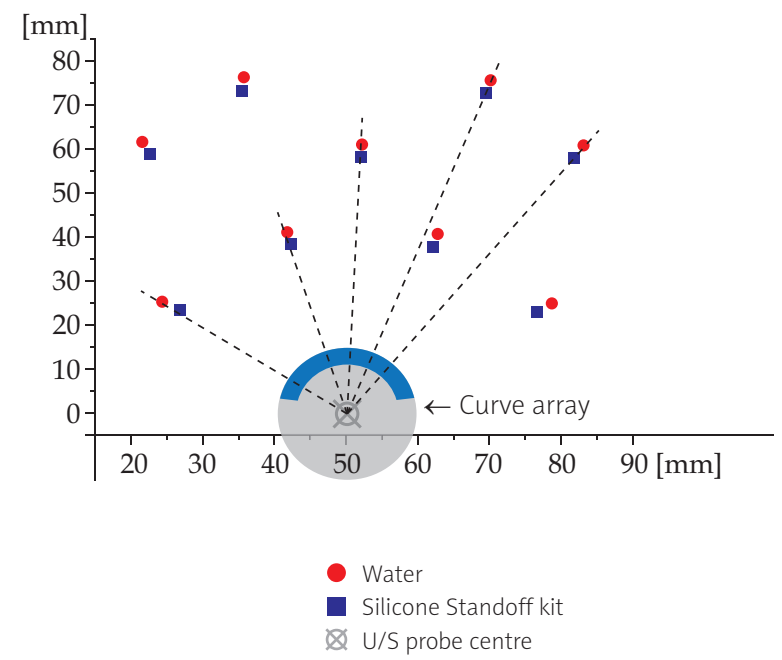

Fig. 6. Radial shift of needles in U/S imaging with the use of Silicone Standoff kit at $5 \mathrm{MHz}$ : a radial needle shift of $3 \mathrm{~mm}$ in direction from U/S probe is observed. Shift is presented according to the reference image acquisition made using an Endocavity balloon filled with water 


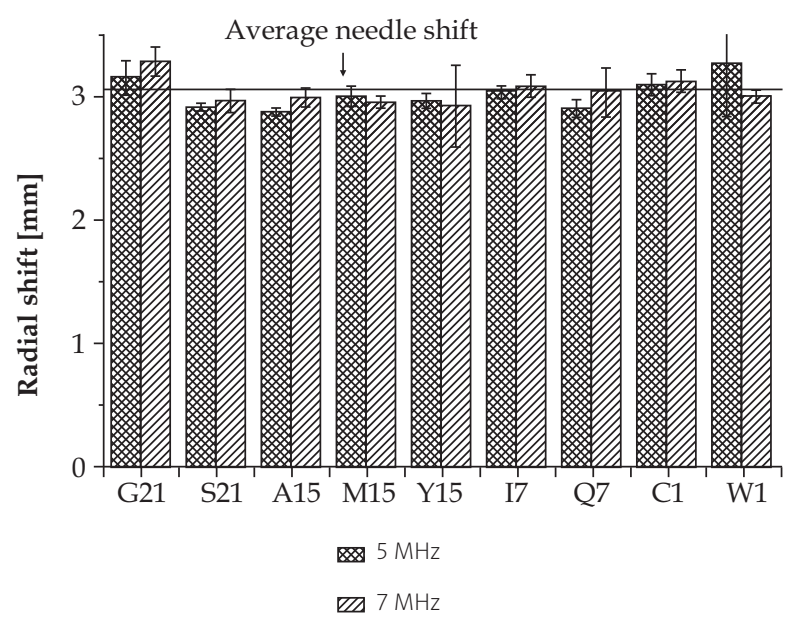

Fig. 7. Needle displacement per template hole at $5 \mathrm{MHz}$ and $7 \mathrm{MHz}$ as the consequence of the application of EA 4015 Silicone Standoff kit on a U/S probe during the image acquisition. Influence of frequency on needle displacement is negligible

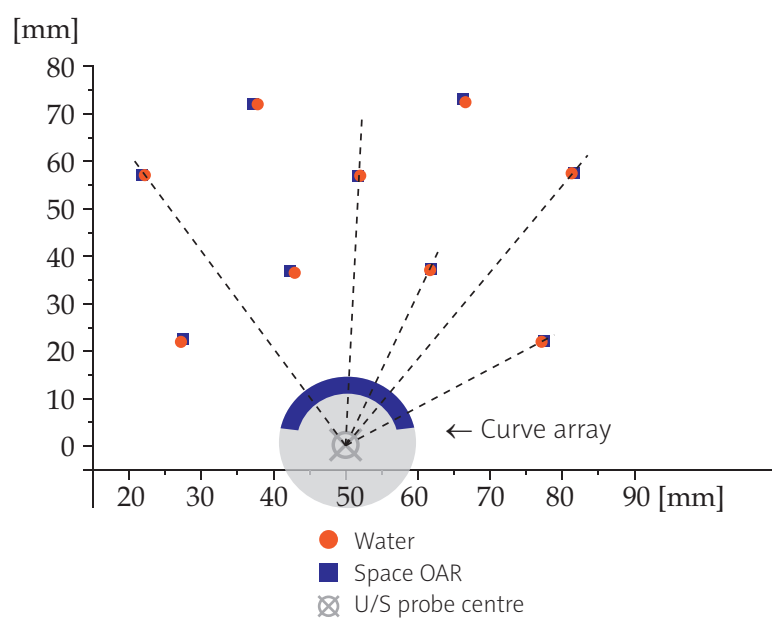

Fig. 9. Effects of the use of Space OAR ${ }^{\mathrm{TM}}$ at $5 \mathrm{MHz}$ on the needles disposition: needles are shifted towards the U/S probe for an average distance of $0.35 \mathrm{~mm}$

the probe and depended only on the wall thickness of the Silicone Standoff kit (Fig. 7). This was precisely what was expected theoretically (see the appendix).

\section{UA0059 Endocavity balloon}

The use of Endocavity balloon filled with water did not cause any significant shift $(0.3 \mathrm{~mm})$ in needle position on images (Table 4). The observed displacement had no specific direction and as such it could be attributed to the uncertainty in reconstruction of the actual position of the needle centre.

\section{Endosgel ${ }^{\circledR}$ in UA0059 Endocavity balloon}

Endosge ${ }^{\circledR}$ along with Endocavity balloon did not affect needle imaging $(0.2 \mathrm{~mm})$ (Table 4$)$. No particular direction of the shifts was observed.

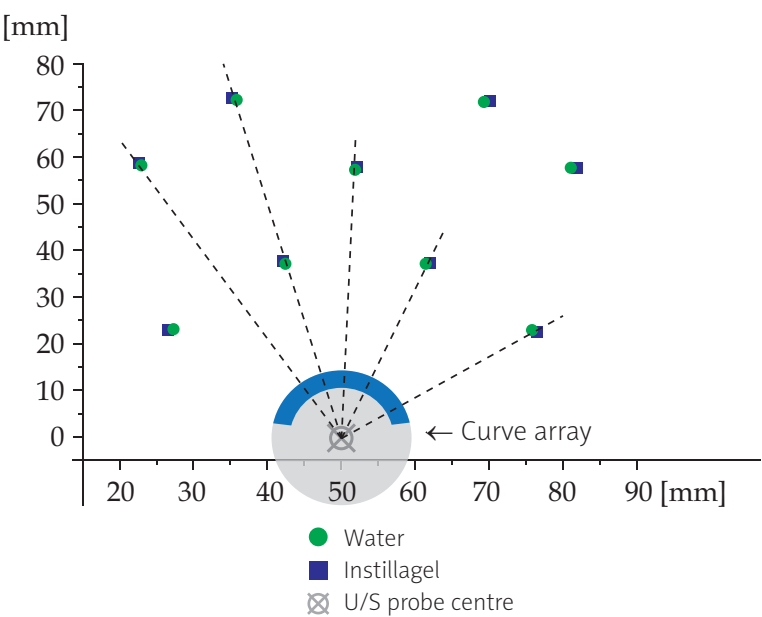

Fig. 8. Effects of insertion of Instillage ${ }^{\circledR}$ in an Endocavity balloon at $5 \mathrm{MHz}$ on the needles disposition: the average disposition of the needles is $0.65 \mathrm{~mm}$ in the radial direction and towards the $\mathrm{U} / \mathrm{S}$ probe

\section{Instillagel $^{\circledR}$ in UA0059 Endocavity balloon}

The insertion of Instilla gel in an Endocavity balloon had obvious effects in needle U/S imaging. The average disposition of the needles was $0.65 \mathrm{~mm}$ in the radial direction and towards the U/S probe (Fig. 8 and Table 4).

\section{Ultraschall gel in UA0059 Endocavity balloon}

Ultraschall gel caused an average image distortion of $0.3 \mathrm{~mm}$. As well as Endosgel, this shift seems to be statistical with no specific direction (Table 4).

\section{Space $O A R^{\mathrm{TM}}$ in UA0059 Endocavity balloon}

Space OAR seems to compress anatomy, as needles were shifted towards the U/S probe for an average distance of $0.35 \mathrm{~mm}$ (Fig. 9 and Table 4).

\section{Prostate volume effect}

Theoretical prostate volume effect with the use of Silicone Standoff kit

We have applied the radial transformation of $3 \mathrm{~mm}$ directed away from EA 4015 Silicone Standoff kit to different cylindrical prostate models (an example is shown in Fig. 10). The resulting transformed volume $\mathrm{V}_{\mathrm{S}}$ was significantly larger from the initial volume $\mathrm{V}_{\mathrm{W}}$. Moreover, the size of this effect depended inversely on the prostate dimensions and its distance from the surface of the ultrasound probe. Our results are presented in Fig. 11.

\section{Experimental estimation of influence of material on prostate volume}

The comparison between the two contoured prostates revealed a deviation in volume of the order of approximately $7.17 \%$. The contouring from the image set from acquisition completed with the help of Endocavity balloon filled with water, resulted with the prostate volume $\left(\mathrm{V}_{\mathrm{W}}: 61979 \mathrm{~mm}^{3}\right)$ of approximately $7.17 \%$ smaller than the one we have ob- 


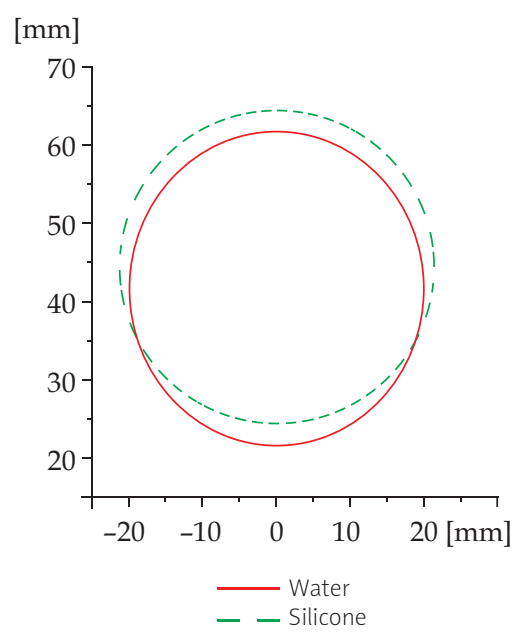

Fig. 10. Prostate shape deformation per slice with the application of EA 4015 Silicone Standoff kit: this example shows radial deformation for an average shape prostate $(\sim 20 \mathrm{~mm})$ and an average distance from probe surface $(\sim 11.8 \mathrm{~mm})$

tained from the image set acquired by covering the ultrasound probe by Silicone Standoff kit ( $\left.\mathrm{V}_{\mathrm{S}}: 66423 \mathrm{~mm}^{3}\right)$ : $\left[\left(1-\mathrm{V}_{\mathrm{S}} / \mathrm{V}_{\mathrm{W}}\right) \times 100 \%\right]$. This result supports our theoretical calculations presented in Fig. 11.

Specifically, in our experimental case we used the tissue equivalent ultrasound prostate phantom of elliptical shape with the major dimension of $53 \mathrm{~mm}$ and the minor dimension of $37 \mathrm{~mm}$. From here we calculated the equivalent radius of $20 \mathrm{~mm}$ [30]. The distance from U/S probe was around $10 \mathrm{~mm}$. The theoretical volume difference for these parameters is $7.23 \%$, see Fig. 11 .

Experimental analysis of dependence of dosimetric parameters on geometrical deformations caused by usage of different materials for US acquisition.

As previously described, we found out that making the acquisition by covering the ultrasound probe by Silicone Standoff kit leads to prostate volume overestimation. We further observed that this geometry alteration of volume and needles possibly leads to dose over/underestimation.

\section{Dose-Volume-Histogram}

By calculating the plans $\mathrm{P}_{1}$ and $\mathrm{P}_{2}$ as defined previously in Material and methods, we found out that the large dose underestimation occurs. Evaluated DVH parameters are presented in Table 5. Plan $\mathrm{P}_{2}$ describes the factual situation, and the $\mathrm{P}_{1}$ shows the result in case of using the Silicon Standoff kit.

\section{COIN}

By observing the COIN, we noted the significant fall down of the COIN value in plan $\mathrm{P}_{2}(0.860)$ comparing to plan $P_{1}(0.810)$, see Table 6 . This means that the use of Silicone Standoff kit as the U/S probe coverage causes considerable overestimation of the COIN value.

The coefficient $c_{1}$ which is the fraction of the PTV (prostate) that is enclosed by the prescription dose, plays insignificant role in this drop of COIN value $\left(0.957\right.$ for $\mathrm{P}_{1}$

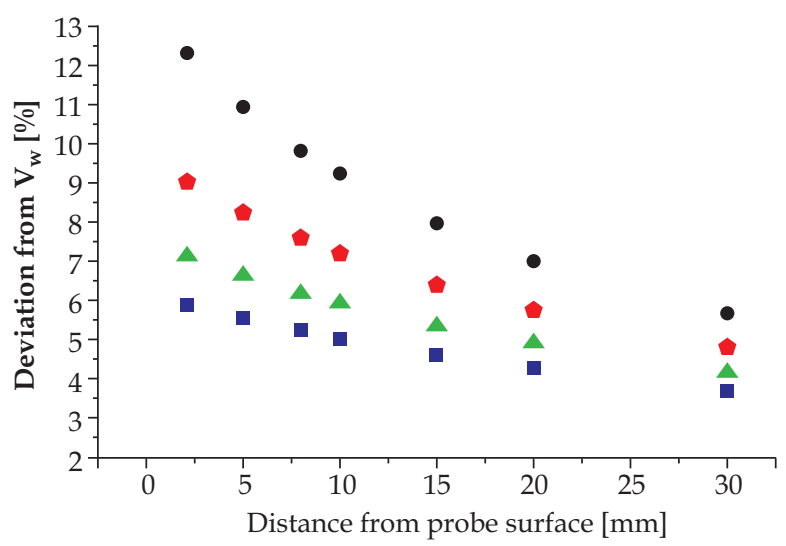

For prostate radius [mm]:

10

$\Delta 30 \square 40$

Fig. 11. Percent volume deviation of spherical models of prostate of various radii and distances from the probe surface, with the application of EA 4015 Silicone Standoff kit

Table 5. Dose-Volume-Histogram parameters derived for the plans $P_{1}$ (based on the image set acquisition made with the U/S probe covered by Silicone Standoff kit) and $\mathrm{P}_{2}$ (U/S probe covered with Endocavity balloon filled with water with dwell times calculated and imported from $\mathrm{P}_{1}$ ). Values in brackets are the relative difference of the parameters between the $\mathrm{P}_{1}$ and $\mathrm{P}_{2}$ in [\%]

\begin{tabular}{|c|c|c|c|}
\hline $\begin{array}{l}\text { DVH- } \\
\text { Parameter }\end{array}$ & $\begin{array}{c}\left(\mathrm{P}_{1}\right) \text { EA } 4015 \\
\text { Silicone Standoff } \\
\left.\text { kit* }^{*} \%\right]\end{array}$ & \multicolumn{2}{|c|}{$\begin{array}{l}\left(\mathrm{P}_{2}\right) \text { UA0059 } \\
\text { Endocavity balloon filled } \\
\text { with water with dwell times } \\
\text { calculated and imported from } \\
\left(\mathrm{P}_{1}\right)^{\star}[\%]\end{array}$} \\
\hline \multicolumn{4}{|l|}{ Prostate } \\
\hline$D_{90}$ & 107.8 & 111.9 & [3.8] \\
\hline$D_{95}$ & 101.4 & 103.5 & {$[2.1]$} \\
\hline $\mathrm{D}_{1 \mathrm{~cm}^{3}}$ & 287.4 & 285.5 & {$[-0.7]$} \\
\hline$V_{100}$ & 95.7 & 96.5 & {$[0.8]$} \\
\hline$V_{120}$ & 70.8 & 77.8 & [9.8] \\
\hline$V_{150}$ & 24.7 & 30.5 & [23.6] \\
\hline$V_{200}$ & 7.1 & 7.9 & [10.8] \\
\hline \multicolumn{4}{|l|}{ Urethra } \\
\hline $\mathrm{D}_{10}$ & 111.7 & 115.0 & [2.9] \\
\hline $\mathrm{D}_{0.1 \mathrm{~cm}^{3}}$ & 114.7 & 115.5 & {$[0.7]$} \\
\hline $\mathrm{D}_{1 \mathrm{~cm}^{3}}$ & 110.2 & 113.2 & [2.7] \\
\hline $\mathrm{D}_{1}$ & 115.2 & 118.1 & [2.5] \\
\hline$V_{100}$ & 65.4 & 70.8 & [8.3] \\
\hline \multicolumn{4}{|l|}{ Rectum } \\
\hline$D_{10}$ & 50.7 & 51.1 & {$[0.8]$} \\
\hline $\mathrm{D}_{0.1 \mathrm{~cm}^{3}}$ & 68.7 & 66.4 & {$[-3.3]$} \\
\hline $\mathrm{D}_{2 \mathrm{~cm}^{3}}$ & 55.4 & 52.5 & {$[-5.2]$} \\
\hline $\mathrm{D}_{1}$ & 65.3 & 64.4 & {$[-1.3]$} \\
\hline
\end{tabular}


Table 6. COIN and External Index values for the plans $P_{1}$ and $P_{2}$

\begin{tabular}{lcc}
$\begin{array}{l}\text { COIN and } \\
\text { COIN factors }\end{array}$ & $\begin{array}{c}\left(P_{1}\right) \text { EA 4015 Silicone } \\
\text { Standoff kit }\end{array}$ & $\begin{array}{c}\left(P_{2}\right) \text { UA0059 Endocavity } \\
\text { balloon filled with water } \\
\text { with dwell times calculated } \\
\text { and imported from }\left(P_{1}\right)\end{array}$ \\
\hline COIN & 0.860 & 0.810 \\
\hline$C_{1}$ & 0.957 & 0.965 \\
\hline$C_{2}$ & 0.899 & 0.840 \\
\hline$C_{3}$ & 1.000 & 0.999 \\
\hline$E I$ & 0.108 & 0.184
\end{tabular}

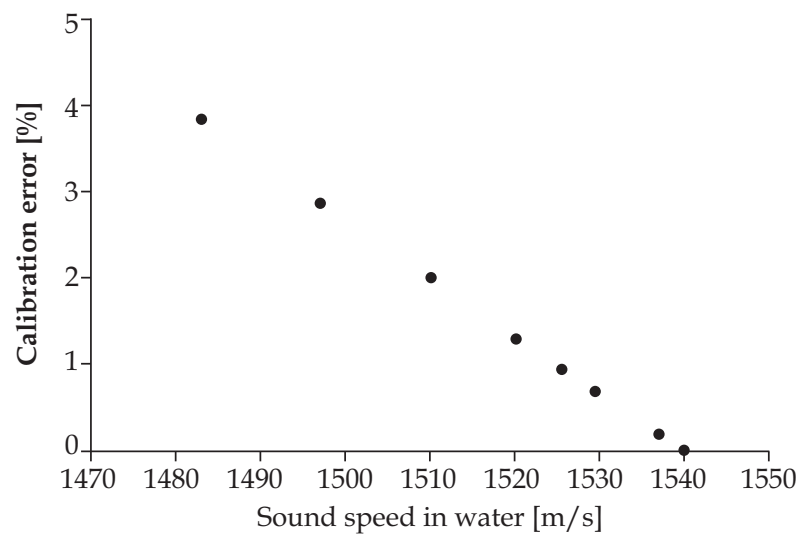

Fig. 12. Predicted calibration error of U/S system in function with speed of sound in tap water (data derived from Chen-Millero equation [14])

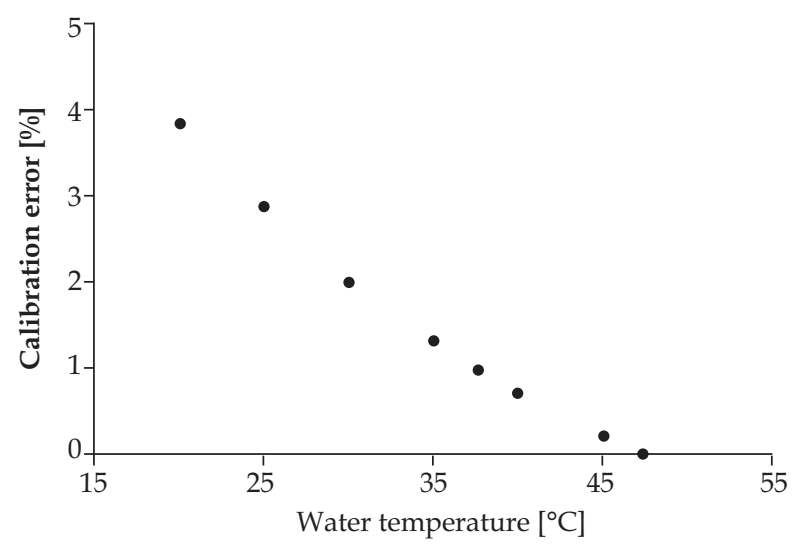

Fig. 13. Predicted calibration error of U/S system in function with temperature in tap water (data derived from Chen-Millero equation [14])

to 0.965 for $\mathrm{P}_{2}$ ). This means that the PTV coverage with prescription dose remains good in both cases. One could expect such a result, as the volume of the prostate used by calculation of plan $P_{2}$ is lesser than that of $P_{1}$ based on which the dwell times were calculated. In this case the COIN coefficient $c_{3}$ has negligible influence on drop of COIN (1.000 for $\mathrm{P}_{1}$ to 0.999 for $\mathrm{P}_{2}$ ), as the dose of OARs has not crossed over the permitted limit defined in our clinical protocol. Main responsibility for the decrease of COIN has the reduction of a factor $c_{2}\left(0.899\right.$ for $\mathrm{P}_{1}$ to 0.840 for $\left.\mathrm{P}_{2}\right)$. This is the consequence of the significant increase of volume of the healthy tissue outside of PTV covered with prescribed dose.

\section{External index (EI)}

Observing the external volume index has just confirmed the results and conclusions we obtained from COIN. The ratio of the normal tissue volume outside of the PTV that receives a dose equal to or greater than the reference dose to the volume of the PTV, is much higher in $\mathrm{P}_{2}$ that was calculated for the original plan $\mathrm{P}_{1}: 0.184$ for $\mathrm{P}_{2}$ compared to 0.108 for $\mathrm{P}_{1}$.

\section{Discussion}

The recorded shift of needles and other organ structures is radial, following the form of the sound wave transmission. There was no distance dependence of the shifts, as needles closer to the probe seem to have the same displacement with those in the edge positions. Additionally, no dependence on frequency was observed. Small deviations among frequencies could be attributed to uncertainty in recording the needle centre coordinates. The greatest shift was observed with the application of the Silicone Standoff kit $(3 \mathrm{~mm})$. This dislocation was expected from the theoretical calculations, due to the difference in sound speed between water and silicone rubber. Silicone Standoff kit makes the needles to appear in larger distances, causing an expansion of geometry. That indicates that using a high-resolution template type TPV 061, where distance between holes is $2.5 \mathrm{~mm}$, a needle could have deviation of more than one hole from its original position. Moreover, the Silicone Standoff kit has the ability to widen the dimensions of every object included in the ultrasound image, as well as altering its shape. In our study we have shown that this image distortion results in an overestimation of a prostate volume which leads as a consequence to the dose underestimation. Instillagel ${ }^{\circledR}$, along with the Endocavity balloon, has an adverse effect to the ultrasound image by "shrinking" objects. Geometry has radial shift directed to U/S probe $(0.7 \mathrm{~mm})$. This can be attributed to the fact that sound waves travel faster through Instillage ${ }^{\circledR}$ than through water. Despite the fact that Ultraschall gel effect in needle shift was insignificant $(0.3 \mathrm{~mm})$ (Table 4), this gel is not recommended to be used as a balloon-filling material as its insertion in the balloon is quite difficult due to its high viscosity. Space OAR ${ }^{\mathrm{TM}}$ also compresses dimensions of appeared objects for an average value of $0.40 \mathrm{~mm}$. This effect has specific direction towards the probe, revealing that speed of sound travels in a higher speed in Space OAR ${ }^{\mathrm{TM}}$ than water. The measured shift can be considered as negligible for clinical application when using layers of up to $5 \mathrm{~mm}$ thickness considered in our study.

Speed of sound at $37.7^{\circ} \mathrm{C}$ in normal water $(1525.4 \mathrm{~m} / \mathrm{s})$ is slightly closer to the speed of sound in soft tissue $(1540 \mathrm{~m} / \mathrm{s})$ than that of pure water $(1524.9 \mathrm{~m} / \mathrm{s})$. Therefore, both normal and distilled water are suitable for quality assurance tests, with the condition of a stable temperature. 
To calibrate accurately U/S system for prostate brachytherapy, biopsy and other interventional procedures, medium with the sound speed of $1540 \mathrm{~m} / \mathrm{s}$ should be available. Goldstein et al. [31] suggests the use of a 9\% ethylene glycol-water mixture instead of tap water in order to eliminate inaccuracy in QA tests in brachytherapy. Sound speed in the suggested mixture is equal to both soft tissue and $U / S$ calibration sound speed $(1540 \mathrm{~m} / \mathrm{s})$ at the room temperature. The errors described in the above-mentioned article $(3.6 \%)$ coincide with the predicted error values $(3.8 \%)$ of Figs. 12 and 13. According to literature available equations, the speed of sound of soft tissue can be achieved when using the tap water by raising the water temperature to $47.4^{\circ} \mathrm{C}$. An additional way is to increase the total dissolved solids or TDS concentration (add some salts) up to $15 \%$, while maintaining temperature at $37.7^{\circ} \mathrm{C}$. To confirm that the above mentioned TDS value has been reached, electrical conductivity (EC) measurements should be performed at $25^{\circ} \mathrm{C}$, until $\mathrm{EC}$ becomes equal to $23.5 \mathrm{mS} / \mathrm{cm}$ (see Equation 1). If nothing of the above is feasible, the potential calibration errors from Figs. 12 and 13 should be taken into account. This expected calibration error is given in dependence of the speed of sound in tap water and the corresponding temperature. The values are derived from Chen-Millero equation [14] and further confirmed by Bilaniuk-Wong's [17], Marczak's [19] and Lubbers-Graaff's [22] equations for sound speed calculation.

\section{Conclusions}

Our study has shown that the EA 4015 Silicone Standoff kit can not be utilized for image acquisition during HDR or LDR prostate brachytherapy, biopsy and other interventional procedures. It leads to erroneous placement and reconstruction of needles, contouring of PTV and OARs. In case of prostate brachytherapy this results in incorrect dose calculation. Effects of all other hydrogel materials can be consider as negligible in the performance of a safe brachytherapy procedure. Furthermore, the accurate performance of QA checks depends on the quality of the water used. If the acoustic velocity of the test water diverts from $1540 \mathrm{~m} / \mathrm{s}$, potential errors may affect accurate calibration of the U/S system. A possible solution to eliminate this deficiency is the choice of the right temperature and salt concentration of the QA water.

\section{Appendix: Theoretical prediction of needle shift}

For the theoretical calculation of expected needle shift, some assumptions were made to simplify the used equations:

1. Every sound signal is generated on the surface of the ultra-sound probe and initiates its transmission with a radius equal to the radius of the probe.

2. Water is $100 \%$ homogeneous with no impurities of any kind (e.g. air bubbles). The salt concentration (salinity) is considered as a feature of the quality of the water, and salts are distributed uniformly throughout its volume.

3. Silicone in Silicone Standoff kit is $100 \%$ homogeneous without any impurities.

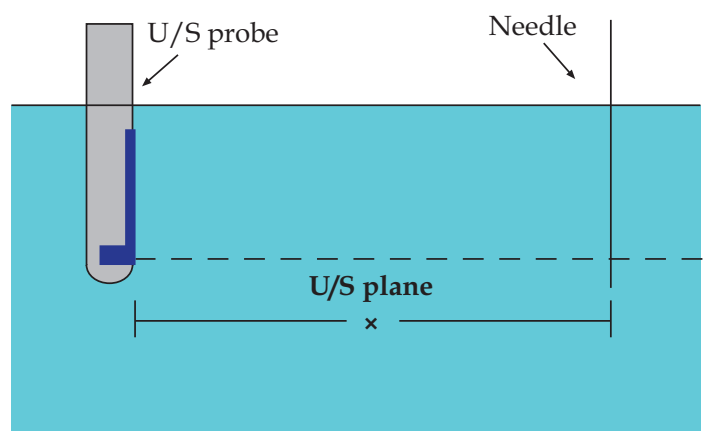

Fig. 14. Probe-needle arrangement in water: $U / S$ probe is placed in the water and a needle is positioned at distance $x$ From U/S probe detector

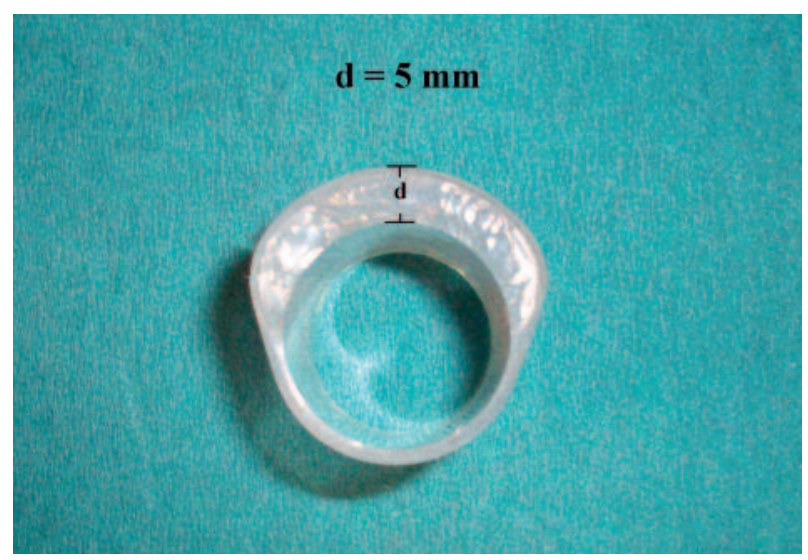

Fig. 15. Axial slice of the EA 4015 Silicone Standoff kit of $5 \mathrm{~mm}$ thickness

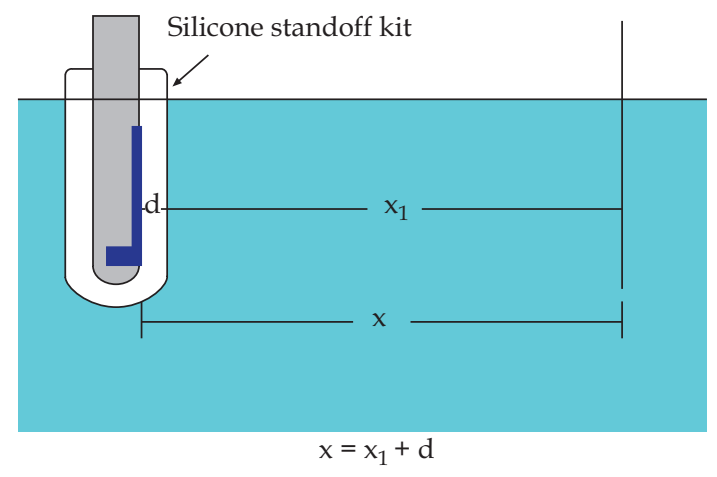

Fig. 16. Probe-needle arrangement in water with the application of EA 4015 Silicone Standoff kit of a thickness d. $\mathrm{U} / \mathrm{S}$ probe is placed in the water and a needle is positioned at distance $\mathrm{x}$ from $\mathrm{U} / \mathrm{S}$ probe detector

4. Temperature of water is the same $\left(37.7^{\circ} \mathrm{C}\right)$ without any gradient throughout water volume and it is independent of time.

5. Water and silicone have the same temperature constantly. 
6. The experiment is considered to be carried out at depth of $15 \mathrm{~cm}$ (Pressure $P=0.101 \mathrm{bar}$ ).

7. The quantity of Endosgel ${ }^{\circledR}$ which is used for Silicone Standoff kit application to the probe is considered negligible and does not affect speed of sound.

8. No air had been inserted between Silicone Standoff kit and probe surfaces.

We assume that the U/S probe is placed in the water and a needle is positioned at distance $x$ from U/S probe detector (see Fig. 14). Considering constant the speed of sound in water for $37.7^{\circ} \mathrm{C}$, a sound wave that emerges from the surface of the probe, travels through the water with velocity $\mathrm{v}_{\mathrm{W}}=1525.4 \mathrm{~m} / \mathrm{s}$. After time $\mathrm{t}_{1}=\mathrm{x} / \mathrm{v}_{\mathrm{w}^{\prime}}$ this sound wave meets the needle and it is reflected instantly. To be received by the US probe it has to travel backwards the same distance $x$. To cross this distance it will have to travel for time $t_{2}=t_{1}=x / v_{W}$. So the moments of emission and reception have a delay time phase of $t=t_{1}+t_{2}$ or

$$
t=\frac{2 x}{v_{w}}
$$

If Silicone Standoff kit with 5.0 mm thickness (Fig. 15) is applied on the probe, sound will have to travel the same distance but through two different media with a different speed (Fig. 16).

The time that the sound wave travels through water (using equation (A1)) is:

$$
\mathrm{t}_{\mathrm{w}}=\frac{2 \mathrm{x}_{1}}{\mathrm{v}_{\mathrm{w}}}
$$

For the time that the sound wave travels through the silicone rubber we have:

$$
\begin{aligned}
& t_{r}=\frac{2 d}{v_{r}} \\
& t_{\text {tot }}=t_{w}+t_{r}
\end{aligned}
$$

where $t_{\text {tot }}$ is the time from emission to reception.

In U/S imaging, time between emission of a sound signal and reception of the reflected signal by the probe is interpreted as the distance of the object that reflects the signal from its source. Considering that sound had travelled through homogeneous soft tissue with speed $\mathrm{v}_{\text {soft tissue }}=1540 \mathrm{~m} / \mathrm{s}$ [22], the difference in delay time with and without the Silicone Standoff kit will corresponds to a displacement of needle position in the acquired ultrasound images.

$$
\text { Needle shift }=x_{w}-x_{r}=\frac{\left[\left(t-t_{\text {tot }}\right) \times v_{\text {soft tissue }}\right]}{2}
$$

Where $x_{w}$ and $x_{r}$ are the positions of needles in the acquired images, without and with the Silicone Standoff kit respectively and

$$
t-t_{\text {tot }}=\left(\frac{2 \times x}{v_{w}}\right)-\left(\frac{2 \times x_{1}}{v_{w}}+\frac{2 \times d}{v_{r}}\right)
$$

Where

$x=x_{1}+d$

From equations (A6) and (A7)

$$
\mathrm{t}-\mathrm{t}_{\text {tot }}=2 \times \mathrm{d} \times\left(\frac{1}{\mathrm{v}_{\mathrm{w}}}-\frac{1}{\mathrm{v}_{\mathrm{r}}}\right)
$$

Therefore,

Needle shift $=\mathrm{d} \times \frac{\mathrm{v}_{\text {soft tissue }}}{\mathrm{v}_{\mathrm{w}}}-\frac{\mathrm{v}_{\text {soft tissue }}}{\mathrm{v}_{\mathrm{r}}}$

Using the speed of sounds values given in the results (theoretical calculations of the speed of sound), expected needle shift is estimated to be equal to $2.80 \mathrm{~mm}$. Moreover, the equation (A9) predicts that needle displacement is independent from needle-probe distance $(x)$ and depends only on the wall thickness $d$ of the Silicone Standoff kit. If instead of $\mathrm{v}_{\text {soft tissue }}=1540 \mathrm{~m} / \mathrm{s}$, the U/S system is used, the actual value of the speed of sound in the medium that the signal had travelled through (in our case normal water $\mathrm{v}_{\mathrm{w}}=1525.4 \mathrm{~m} / \mathrm{s}$ ), then equation (A9) would become:

$$
\begin{aligned}
& \text { Needle shift }=\mathrm{d} \times\left(\frac{\mathrm{v}_{\mathrm{w}}}{\mathrm{v}_{\mathrm{w}}}-\frac{\mathrm{v}_{\mathrm{w}}}{\mathrm{v}_{\mathrm{r}}}\right) \Rightarrow \\
& \Rightarrow \text { Needle shift }=\mathrm{d} \times\left(1-\frac{\mathrm{v}_{\mathrm{w}}}{\mathrm{v}_{\mathrm{r}}}\right)
\end{aligned}
$$

In this case, expected needle displacement is $2.77 \mathrm{~mm}$.

\section{Acknowledgements}

This work has been realised within the Project BiopSee (HA-Project-Nr.: 199/09-9), supported within the framework of Hessen Model Projects by means of the European Union (European Funds for Regional Development - EFRE) and of the State Hessen in Germany.

Part of this work was presented as a Poster at the ESTRO Anniversary Conference held in London, UK from 8-12 May 2011 and was a winner of the GEC-ESTRO Best Poster Award.

\section{Disclosure}

The authors have declared no conflict of interest.

\section{References}

1. Damore SJ, Syed N, Puthawala AA et al. Needle displacement during HDR brachytherapy in the treatment of prostate cancer. Int J Radiat Oncol Biol Phys 2000; 46: 1205-1211. 
2. Martinez AA, Pataki I, Edmundson G et al. Phase II prospective study of the use of conformal high-dose-rate brachytherapy as monotherapy for the treatment of favourable stage prostate cancer: a feasibility report. Int J Radiat Oncol Biol Phys 2001; 49: 61-69.

3. Mullokandov E, Gejerman G. Analysis of serial CT scans to assess template and catheter movement in prostate HDR brachytherapy. Int J Radiat Oncol Biol Phys 2004; 58: 1063-1071.

4. Hoskin PJ, Bownes PJ, Ostler P et al. High dose rate afterloading brachytherapy for prostate cancer: catheter and gland movement between fractions. Radiother Oncol 2003; 68: 285-288.

5. Simnor T, Li S, Lowe G et al. Justification for inter-fraction correction of catheter movement in fractionated high dose-rate brachytherapy treatment of prostate cancer. Radiother Oncol 2009; 93: 253-258.

6. Yoshida K, Yamazaki H, Nose T et al. Needle applicator displacement during high-dose-rate interstitial brachytherapy for prostate cancer. Brachytherapy 2010; 9: 36-41.

7. Kälkner KM, Nilsson J, Lundell M et al. Prostate displacement kit: reducing the radiation dose to the rectum. Radiother Oncol 2006; 81: 291-293.

8. Kim Y, Hsu I-CJ, Lessard E et al. Measurement of craniocaudal catheter displacement between fractions in computed tomography-based high dose rate brachytherapy of the prostate cancer. J Appl Clin Med Phys 2007; 8: 1-13.

9. Kim Y, Hsu I-CJ, Pouliot J. Dose uncertainty due to computer tomography (CT) slice thickness in CT-based high dose rate brachytherapy of the prostate cancer. Med Phys 2004; 31: 25432548.

10. Susil RC, Mc Nutt TR, De Wesse TL et al. Effects of prostaterectum separation on rectal dose from external beam radiotherapy. Int J Radiat Oncol Biol Phys 2010; 76: 1251-1258.

11. Napolitano D, Chou C-H, McLaughlin G et al. Sound speed correction in ultrasound imaging. Ultrasonics 2006; 44: 43-46.

12. Pfeiffer D, Sutlief S, Feng W et al. AAPM Task group 128: Quality assurance tests for prostate brachytherapy ultrasound systems. Med Phys 2008; 35: 5471-5489.

13. McCutcheon SC, Martin JL, Barnwell TO Jr. Water quality in Maidment, D.R. Handbook of Hydrology. McGraw-Hill, New York 1993, p. 113

14. Chen C-T, Millero FJ. Speed of sound in seawater at high pressures. J Acoust Soc Am 1977; 62: 1129-1135.

15. Hachiya H, Ohtsuki S, Tanaka M et al. Determination of sound speed in biological tissues based on frequency analysis of pulse response. J Acoust Soc Am 1992; 92: 1564-1568.

16. Wong GSK, Zhu S. Speed of sound in seawater as a function of salinity, temperature and pressure. J Acoust Soc Am 1995; 97: 1732-1736.

17. Bilaniuk N, Wong GSK. Speed of sound in pure water as a function of temperature. J Acoust Soc Am 1993; 93: 1609-1612, as amended by Bilaniuk N, Wong GSK (1996), Erratum: Speed of sound in pure water as a function of temperature. J Acoust Soc Am 1993; 93: 1609-1612). J Acoust Soc Am 1996; 99: 3257.

18. Del Grosso VA, Mader CW. Speed of sound in pure water. I Acoust Soc Am 1972; 52: 1442-1446.

19. Marczak W. Water as a standard in the measurement of speed of sound in liquids. J Acoust Soc Am 1997; 102: 2776-2779.

20. Kroebel W, Mahrt K-H. Resent results of absolute sound velocity measurements in pure water and sea water at atmospheric pressure. Acoustica 1976; 35: 154-164.

21. Fujii K, Masui R. Accurate measurements of the sound velocity in pure water by combining a coherent phase-detection technique and a variable path length interferometer. J Acoust Soc Am 1993; 93: 276-282.

22. Lubbers J, Graaff R. A simple and accurate formula for the sound velocity in water. Ultrasound Med Biol 1998; 24: 1065 1068.
23. Belogol'ski VA, Sekoyan SS, Samorukova LM et al. Pressure dependence of the sound velocity in distilled water. Measurements Techniques 1999; 42: 406-413.

24. Kolkman RGM, Steenbergen W, Van Leeuwen TG. Reflection mode photoacoustic measurement of speed of sound. Optics Express 2007; 15: 3291-3300.

25. Karabis A, Giannouli S, Baltas D. HIPO: A hybrid inverse treatment planning optimization algorithm in HDR Brachytherapy. Radiother Oncol 2005; 76 Supplement 2: 29.

26. Baltas D, Kolotas C, Geramani K et al. A conformal index (COIN) to evaluate implant quality and dose specification in brachytherapy. Int J Radiat Oncol Biol Phys 1998; 40: 515-524.

27. Meertens H, Borger J, Steggerda $M$ et al. Evaluation and optimization of interstitial brachytherapy dose distribution. In: Mould RF, Battermann JJ, Martinez AA, Speiser BL (eds.). Brachytherapy from radium to optimization. Veenendaal, The Netherlands: Nucletron International. 1994; 300-306.

28. Mavroidis P, Katsilieri Z, Kefala V et al. Radiobiological evaluation of the influence of dwell time modulation restriction in HIPO optimized HDR prostate brachytherapy implants. J Contemp Brachyther 2010; 2: 117-128.

29. Milickovic N, Nikolova I, Tselis N et al. Influence of patient movement and anatomy alteration on the quality of the 3D USbased prostate HDR brachytherapy treatment. World Congress on Medical Physics and Biomedical Engineering, September 7-12, 2009, Munich, Germany, IFMBE Proceedings, Vol. 25/I, edited by O. Dössel and W.C. Schlegel (Springer Berlin Heidelberg, Berlin, Heidelberg, 2009), 484-487.

30. Heyt JW, Diaz MJ. Pressure drop in flat oval spiral air duct. ASHRAE Transactions 1975; 81: 221-232.

31. Goldstein A, Yudelev M, Sharma PK et al. Design of Quality Assurance for Sonographic Prostate Brachytherapy Needle Guides. J Ultrasound Med 2002; 21: 947-954. 